\title{
A new phytoecdysteroid from the stem bark of Vitex cienkowskii
}

\author{
Timo D. Stark ${ }^{1}$ (D) Julius Rami ${ }^{1}$ - Sonja Fröhlich ${ }^{1}$ - Patrick Weiss ${ }^{1} \cdot$ Wolfgang Vierling $^{2} \cdot$ Alain B. Dongmo $^{3}$. \\ Thomas Hofmann ${ }^{1}$
}

Received: 30 April 2020 / Revised: 12 August 2020 / Accepted: 16 August 2020 / Published online: 20 August 2020

(C) The Author(s) 2020

\begin{abstract}
To investigate differences in the metabolome of the stem bark of Vitex cienkowskii harvested at three different locations and three different seasons, their extracts were analyzed by means of UPLC-ESI-IMS-TOF MS ${ }^{\mathrm{e}}$. One marker metabolite was isolated and chemically characterized, which was identified as the new compound 20,24-dihydroxy,24-hydroxymethylecdysone (1). IMS showed two drift time species for $\mathbf{1}$ which could be used as new and additional characteristic compound parameters in compound identification to reduce dereplication and false positives.
\end{abstract}

Keywords Non-targeted UPLC-ESI-IMS-TOF-MS profiling · 20,24-Dihydroxy,24-hydroxymethylecdysone $\cdot$ Ion mobility $\cdot$ CCS $\cdot$ Conformers

\section{Introduction}

About 250 known species of tropical and subtropical trees and shrubs of the genus Vitex are known which belongs to the family of Verbenaceae [1]. Vitex species has been reported to be applied in the traditional medicine to treat a wide range of diseases, such as malaria, asthma, wounds, allergy, depression, venereal and skin diseases, snake bite, and body pain [2]. Cameroonian traditional healers describe Vitex cienkowskii Kotschy and Peyritsch as one of the most popular plants widely used in many disorders. Previous phytochemical studies revealed the identification of diterpenoids [3-6], iridoid glycosides [7, 8], oils [9], flavonoids [6, 10, 11], ceramide [12], and ecdysteroids [7, 13, 14].

Electronic supplementary material The online version of this article (https://doi.org/10.1007/s00217-020-03591-z) contains supplementary material, which is available to authorized users.

Timo D. Stark

timo.stark@tum.de

1 Lehrstuhl für Lebensmittelchemie und Molekulare Sensorik, Technische Universität München, Lise-Meitner-Str. 34, 85354 Freising, Germany

2 Institut für Pharmakologie und Toxikologie, Technische Universität München, Biedersteiner Str. 29, 80802 Munich, Germany

3 Department of Animal Biology, Faculty of Science, University of Douala, P.O. Box 24157, Douala, Cameroon
Ultra performance liquid chromatography (UPLC) in combination with Time-of-Flight (TOF) mass spectrometry (MS) is one of the methods of choice for unbiased, fast and sensitive compound screening, fulfills high-throughput demand, and enables the qualification of bioactives and dietary biomarkers with high accuracy [15-18]. MS combined with ion mobility spectrometry (IMS) could resolve ions that may be indistinguishable by MS alone, or to determine structural information like rotationally averaged collision cross-sectional area (CCS). Very recently, we highlighted for several compounds more than one CCS, which we proposed to be hydrogen-bond stabilized rotational isomers in the gas phase. We concluded to use all CCS values of one compound, and we propose to add also the intensity ratio of the conformers as a new and additional characteristic compound parameter in compound identification/screening/database applications to reduce dereplication and false positives, and strengthen the identification [19].

In this study, we performed a complete metabolomic workflow on $V$. cienkowskii with the aim of highlighting the similarities and/or differences in the metabolite composition of aqueous ethanolic extracts taken from stem bark of different regions (Foumbot F, Lelem Mouantong LM, Njimom NJ) as well as at different harvest periods (1-3) to identify on one hand which period might be the best for isolation of known lead compounds and on the other hand to screen and identify geographic and/or harvesting period marker compounds. Thus, one marker compound 
was isolated and characterized via MS as well as 1D- and 2D-NMR spectroscopy.

\section{Materials and methods}

\section{Chemicals}

$\mathrm{H}_{2} \mathrm{O}$ for chromatographic separations was purified with a Milli-Q Gradient A10 system (Millipore, Schwalbach, Germany), and solvents used were of HPLC-MS grade (Merck, Darmstadt, Germany). Deuterated solvents for NMR experiments were obtained from Sigma-Aldrich (Steinheim, Germany).

\section{Plant material}

The stem bark of $V$. cienkowskii was collected in Foumbot $(\mathrm{F}$, coordinates $05^{\circ} 35.911^{\prime} \mathrm{N}$; $010^{\circ} 41.346^{\prime} \mathrm{E}$ ), Lelem Mouantong ( $\mathrm{LM}$, coordinates $05^{\circ} 11.321^{\prime} \mathrm{N}$; 009 $59.647^{\prime} \mathrm{E}$ ), as well as Njimom (NJ, coordinates $05^{\circ} 48.830^{\prime} \mathrm{N} ; 011^{\circ} 01.111^{\prime} \mathrm{E}$ ), Cameroon, in 2013 end of October (end of raining season, 1), June (mid of raining season, 2), and January (mid of dry season, 3) from the same trees and same time, and identified at the National Herbarium, Yaoundé Cameroon, where a voucher specimen (number $32721 \mathrm{HNC}$ ) is deposited for future reference. The stem bark was air-dried for 14 days and then pulverized to a fine powder.

\section{Extraction and isolation}

Vitex cienkowskii bark powder from Foumbot $(50 \mathrm{~g})$ was suspended in a mixture of ethanol/water $(2 \times 200 \mathrm{ml}, 70 / 30$, $\mathrm{v} / \mathrm{v})$, sonicated (15 min), stirred at RT (20 min), and filtered. The filtrate was extracted with hexane $(2 \times 200 \mathrm{ml})$, the etha$\mathrm{nol} /$ water extract was evaporated, and then, the sample was freeze-dried. Aliquots ( $1 \mathrm{~g}$ ) of the freeze-dried ethanol/water extract were dissolved in a water/methanol mixture $(10 \mathrm{ml}$, $50 / 50, \mathrm{v} / \mathrm{v}$ ) and fractionated by means of HPLC using a preparative HPLC system (PrepStar, Varian, Darmstadt, Germany). Chromatography was performed $(\lambda=270 \mathrm{~nm})$ using an RP column $(21.2 \times 250 \mathrm{~mm}$, phenylhexyl, $5 \mu \mathrm{m}$; Phenomenex, Aschaffenburg, Germany) as the stationary phase, starting with a mixture $(99 / 1, \mathrm{v} / \mathrm{v})$ of aqueous formic acid $(0.1 \%$ in water, $\mathrm{pH} 2.5)$ and $\mathrm{ACN}$ increasing the $\mathrm{ACN}$ content up to $80 \%$ within $20 \mathrm{~min}$, and in $1 \mathrm{~min}$ to $100 \%$. Three fractions (F1-1-3) were collected, concentrated under reduced pressure, and freeze-dried. Repurification of F1-2 and -3 was performed using ThermoHypersil ODS $(10 \times 250 \mathrm{~mm}, 5 \mu \mathrm{m}$; Kleinostheim, Germany) as the stationary phase. The effluent $(4.0 \mathrm{ml} / \mathrm{min})$ was monitored at $270 \mathrm{~nm}$ and an isocratic gradient consisting of a mixture $(79 / 21, v / v)$ of aqueous $\mathrm{HCO}_{2} \mathrm{H}\left(0.1 \%\right.$ in $\left.\mathrm{H}_{2} \mathrm{O}\right)$ and
$\mathrm{ACN}$ was applied. Collected fractions at the retention time of $7.5 \mathrm{~min}$ were concentrated under reduced pressure and freeze-dried twice, affording 1: colorless powder; HRESIMS $\mathrm{m} / \mathrm{z} 525.3069[\mathrm{M}-\mathrm{H}]^{-}$(calcd for $\left.\mathrm{C}_{28} \mathrm{H}_{47} \mathrm{O}_{9}, 525.3064\right) ;{ }^{1} \mathrm{H}$ NMR (DMSO- $d_{6}, 27^{\circ} \mathrm{C}, 400 \mathrm{MHz}$ ) data, see Table $\mathrm{S} 1 ;{ }^{13} \mathrm{C}$ NMR (DMSO- $d_{6}, 27^{\circ} \mathrm{C}, 100 \mathrm{MHz}$ ) data, see Table S2.

\section{Ultra performance liquid chromatography- electrospray ionisation-ion mobility-time-of-flight mass spectrometry (UPLC-ESI-IM-TOF MS)}

Aliquots $(2 \mu \mathrm{l})$ of the extracts $(5 \mathrm{mg} / 2 \mathrm{ml}, 50 \% \mathrm{MeCN}$, each) were vortexed $(1 \mathrm{~min})$, sonicated $(10 \mathrm{~min})$, centrifuged (5000 rpm, $10 \mathrm{~min})$, membrane-filtered $(0.20 \mu \mathrm{m})$, and analyzed in five replicates by means of UPLC-ESI-TWIMS-TOF MS on a Waters Vion HDMS mass spectrometer (Waters, Manchester) coupled to an Acquity i-class UPLC system (Waters, Milford) equipped with a $2 \times 150 \mathrm{~mm}, 1.7 \mu \mathrm{m}, \mathrm{BEH}$ C18 column (Waters) consisting of a binary solvent manager, sample manager, and column oven. Operated with a flow rate of $0.4 \mathrm{ml} / \mathrm{min}$ at $45{ }^{\circ} \mathrm{C}$, the following gradient was used for chromatography: starting with a mixture $\left(15 / 85\right.$, v/v) of aqueous $\mathrm{HCO}_{2} \mathrm{H}$ $\left(0.1 \%\right.$ in $\left.\mathrm{H}_{2} \mathrm{O}\right)$ and $\mathrm{MeCN}\left(0.1 \% \mathrm{HCO}_{2} \mathrm{H}\right)$, the $\mathrm{MeCN}$ content was increased to $90 \%$ within $8 \mathrm{~min}$, to $100 \%$ within 4 min, kept constant for $5 \mathrm{~min}$, decreased to $15 \%$ within $0.4 \mathrm{~min}$, and finally kept constant for $0.6 \mathrm{~min}$ at $15 \%$. Scan time for the $\mathrm{HDMS}^{\mathrm{e}}$ method was set to $1.0 \mathrm{~s}$. Analyses were performed in ESI sensitivity mode using the following ion source parameters: capillary voltage $2.3 \mathrm{kV}$ in negative mode and $3.0 \mathrm{kV}$ in positive mode, source temperature $120^{\circ} \mathrm{C}$, desolvation temperature $550{ }^{\circ} \mathrm{C}$, cone gas flow $50 \mathrm{l} / \mathrm{h}$, and desolvation gas $900 \mathrm{l} / \mathrm{h}$. Data processing was performed using UNIFI 1.8 (Waters). All data were lock mass corrected on the pentapeptide leucine enkephalin (Tyr-Gly-Gly-Phe-Leu, $m / z$ 554.2615, $[\mathrm{M}-\mathrm{H}]^{-}$) in a solution $(50 \mathrm{pg} / \mu \mathrm{l})$ of $\mathrm{ACN} / 0.1 \% \mathrm{HCO}_{2} \mathrm{H}(1 / 1, \mathrm{v} / \mathrm{v})$. Scan time for the lock mass was set to $2.0 \mathrm{~s}$ with an interval of $0.5 \mathrm{~min}$. Calibration of the Vion in the range from $\mathrm{m} / \mathrm{z} 50$ to 1200 was performed using a solution of the MajorMix ${ }^{\mathrm{TM}}$ (Waters). The UPLC and Vion systems were operated with UNIFI ${ }^{\mathrm{TM}}$ software (Waters). Collision energy ramp for $\mathrm{HDMS}^{\mathrm{e}}$ was set from 20 to $30 \mathrm{eV}$. Further details of the Vion IMS qTof instrument and processing and detection parameters are listed in the Supplementary Material (SM, Table S3). The raw data obtained from UPLC-ESI-IMS-TOF MS analysis were processed with Progenesis QI using the following peak picking conditions: all runs, limits automatic, sensitivity 3 , and retention time limits $0.5-17 \mathrm{~min}$. Compounds used for principal components analysis (PCA) were filtered by means of Anova $p$ value $\leq 0.01$ and a fold change of $\geq 5$. The processed data was exported to EZinfo where the matrix was analyzed by PCA with pareto scaling. Group differences 
were calculated using orthogonal partial least-squares discriminant analysis (OPLS-DA) highlighted as S plots.

\section{Nuclear magnetic resonance spectroscopy}

1D and 2D NMR spectroscopy ${ }^{1} \mathrm{H},{ }^{1} \mathrm{H}-{ }^{1} \mathrm{H}-g \mathrm{COSY}, g \mathrm{HSQC}$, $g \mathrm{HMBC}$, and ${ }^{13} \mathrm{C}$ were performed on an Avance III $400 \mathrm{MHz}$ spectrometer with a BBO probe (Bruker, Rheinstetten, Germany).

\section{Results and discussion}

As $V$. cienkowskii is one of the most popular plants widely used in many disorders in Cameroon [1, 7, 12], the question arose as to whether the aqueous ethanolic stem bark extract of three different located trees and three different harvesting periods might be differing in its chemical composition.

To investigate the metabolites composition, we conducted an untargeted metabolomic approach using UPLC-ESI-TWIMS-TOF MS with simultaneous acquisition of low- and high-collision energy mass spectra $\left(\mathrm{MS}^{\mathrm{e}}\right)$. Using the Progenesis QI workflow consisting of import data, review alignment, experiment design setup, peak picking, review deconvolution, review compounds, and compounds statistics, unsupervised statistics were performed to evaluate if any differences in the metabolomes were detectable. Compounds used for PCA were filtered by means of Anova $p$ value $\leq 0.01$ and fold change of $\geq 5$ resulted in the PCA displayed in Fig. 1. Analysis of each stem bark extract in five replicates showed a rather good clustering of each replicate in close proximity, thus confirming the reproducibility of the UPLC-ESI-TWIMS-TOF MS profiling method. Inspection of the PCA output illustrated that the largest differences were observed between LM1 and F2 along PC1, whilst NJ 1, 3 and F1 could be clearly separated along PC2 from all other samples (Fig. 1). To visualize similarities and differences between region and/or harvesting period, $\mathrm{S}$ plots of data pairs of accurate mass and retention time of each metabolite were calculated (Fig. 2). As the $y$-axis of the $S$ plot denotes confidence of a metabolite's contribution to the group difference and the $x$-axis denotes the contribution of a particular metabolite to the group difference, the S plots of F1 vs F3 indicate the ion $m / z 525.3067$ (1) showing by far the highest difference between the harvest periods (Fig. 2). The trend plot of all three locations and harvest periods for $\mathrm{m} / \mathrm{z} 525.3067$ is summarized in Fig. 3. Based on the relative abundance of the compound, F1 represents the best material to isolate 1. In fact, in F2 and F3 as well as LM1 and LM3, compound 1 was not detectable with this approach. In contrast, NJ1-3 and LM2 contained minor amounts of 1. Consequently, differences between the regions Foumbot, Lelem Mouantong, and Njimom and/or harvesting periods could be detected, but the whole data give no clear picture. This observation is supported by other metabolites gained by means of S plot as well as trend plot (data not shown) as either, e.g., for $\mathbf{1}$ in all Foumbot samples or in all samples from the same season/period, a similar abundance could be expected. Here, more biological replicates and/or a method for the accurate quantitation of $\mathbf{1}$ might be helpful in the future.

Therefore, compound 1 (Fig. 4) was isolated via preparative and semi-preparative HPLC from F1 as a colorless powder and showed a pseudomolecular ion peak $\mathrm{m} / z 525.3069$ $[\mathrm{M}-\mathrm{H}]^{-}$(calcd. 525.3064, +0.6 ppm) in the HR-ESI-MS (Fig. S2, S3, SM), corresponding to the molecular formula of $\mathrm{C}_{28} \mathrm{H}_{46} \mathrm{O}_{9}$. The high-collision energy mass spectrum $\left(\mathrm{MS}^{\mathrm{e}}\right.$ ) (Fig. S4-S6, SM) highlighted characteristic $\mathrm{m} / \mathrm{z}$ of $479.3007\left(\mathrm{C}_{27} \mathrm{H}_{43} \mathrm{O}_{7}\right), 319.1905\left(\mathrm{C}_{19} \mathrm{H}_{27} \mathrm{O}_{4}\right), 301.1797$ $\left(\mathrm{C}_{19} \mathrm{H}_{25} \mathrm{O}_{3}\right)$, and $159.1017\left(\mathrm{C}_{8} \mathrm{H}_{15} \mathrm{O}_{3}\right)$ which are in line with the chemical structure displayed in Fig. 4 and 5 as well as Figs. S4-S6, SM.

The ${ }^{1} \mathrm{H}$ NMR features of compound 1 were indicative of an ecdysteroid, revealing a number of ${ }^{1} \mathrm{H}$ NMR signals highlighting similarities in both the splitting patterns as well as chemical shift values as compared with those of pinnatasterone and 24-epi-pinnasterone [20], makisterone C, 20-hydroxyecdysone and 20-hydroxy,24-hydroxymethylecdysone [21],

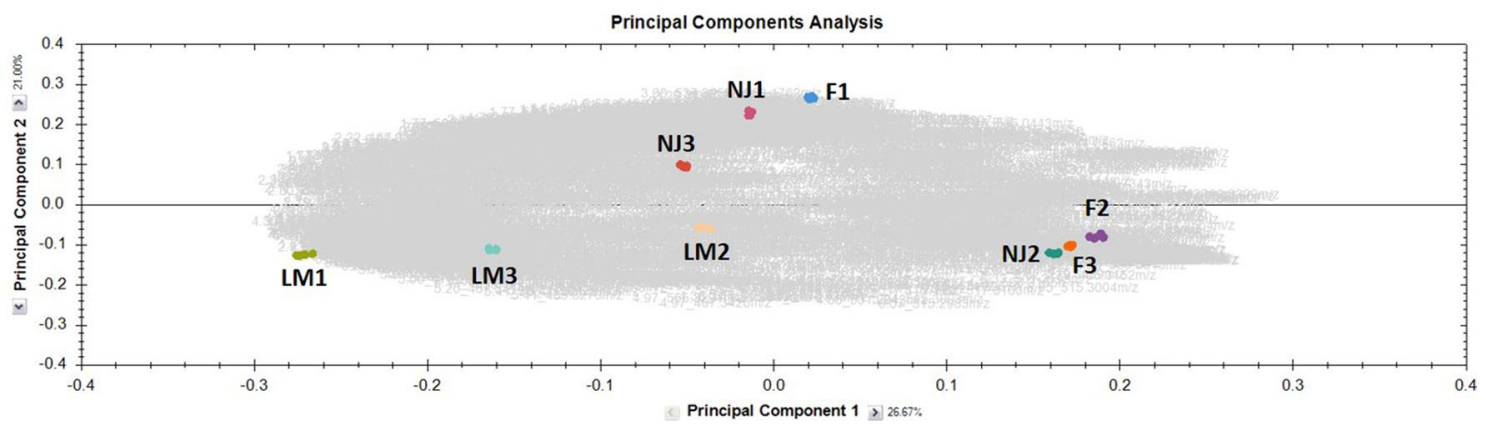

Fig. 1 Score plot (comp [1] vs. comp [2]) of UPLC-ESI-TWIMS-TOF MS full-scan analysis (50-1200 Da, ESI ${ }^{-}$, sensitivity resolution mode) of $V$. cienkowskii stem bark extract of different regions as well as harvesting times (five replicates per sample) 


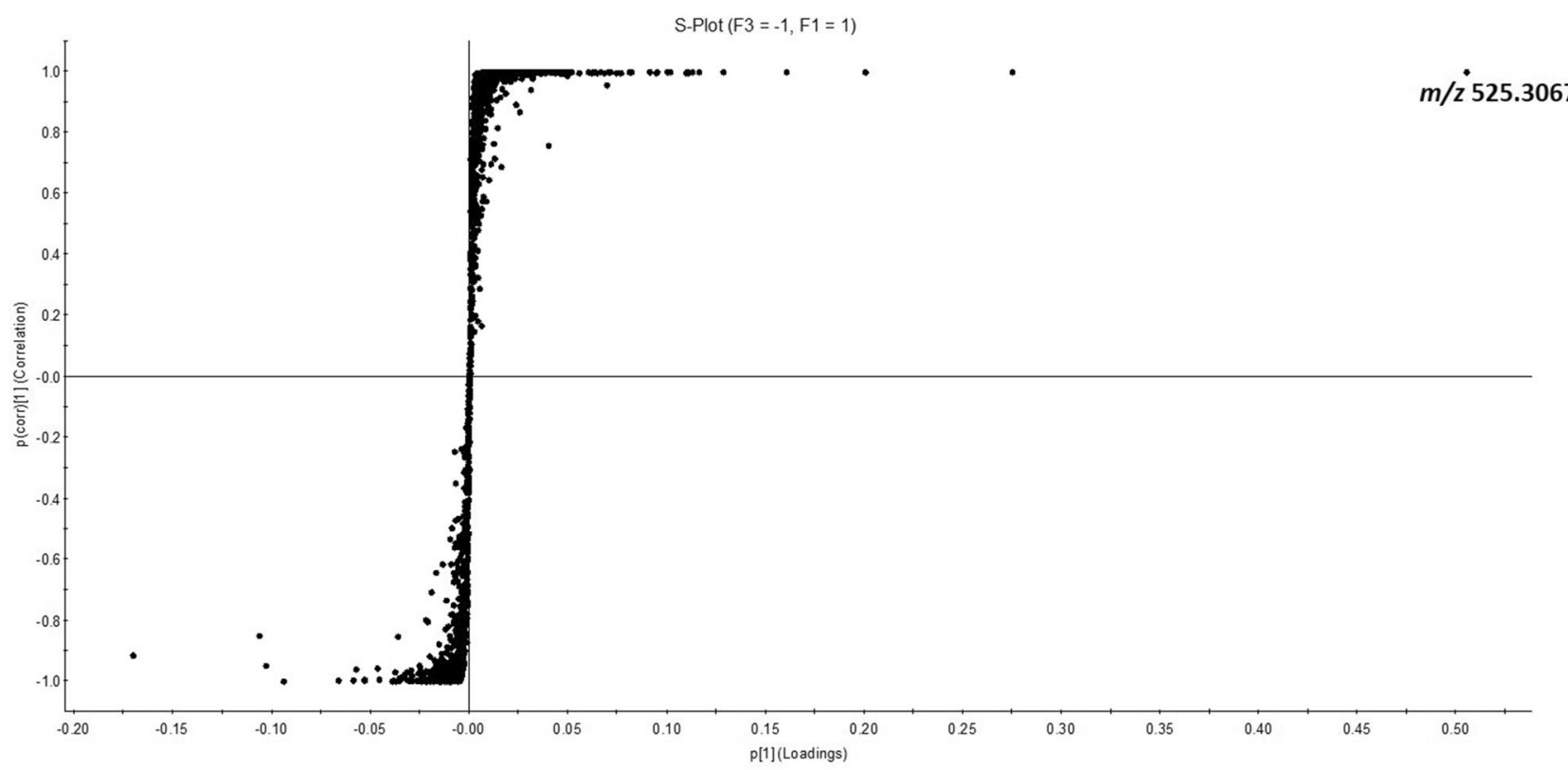

Fig. 2 S-Plot of F1 vs. F3 stem bark extract

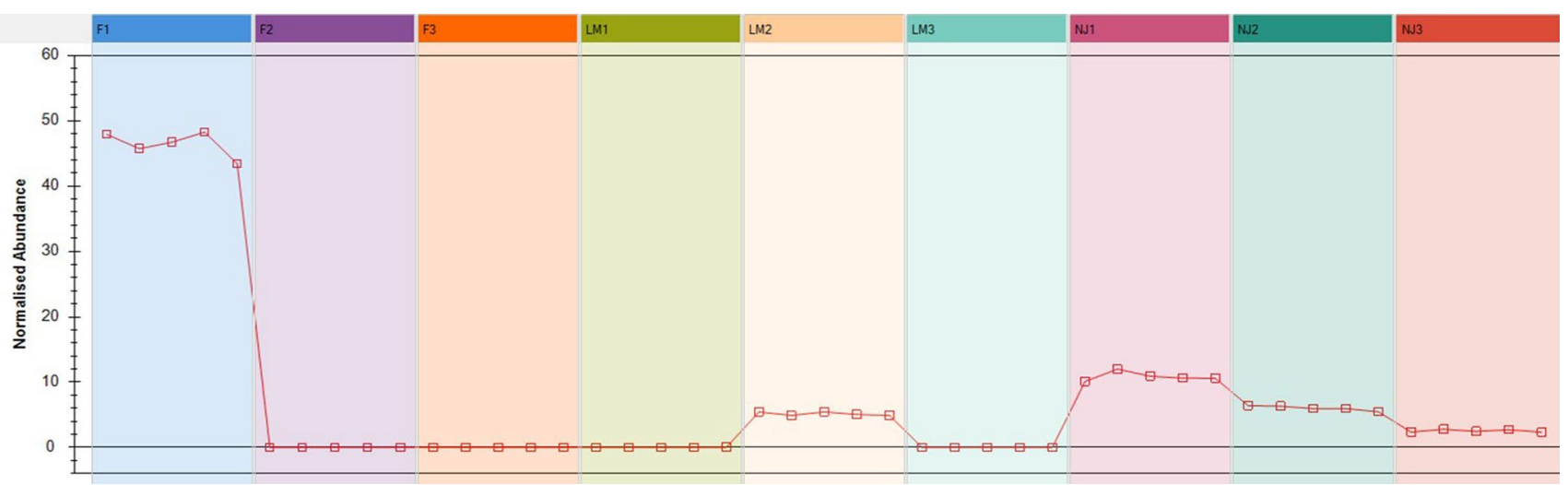

Fig. 3 Chemometric trend plot illustrating normalized abundance (area) of compound 1

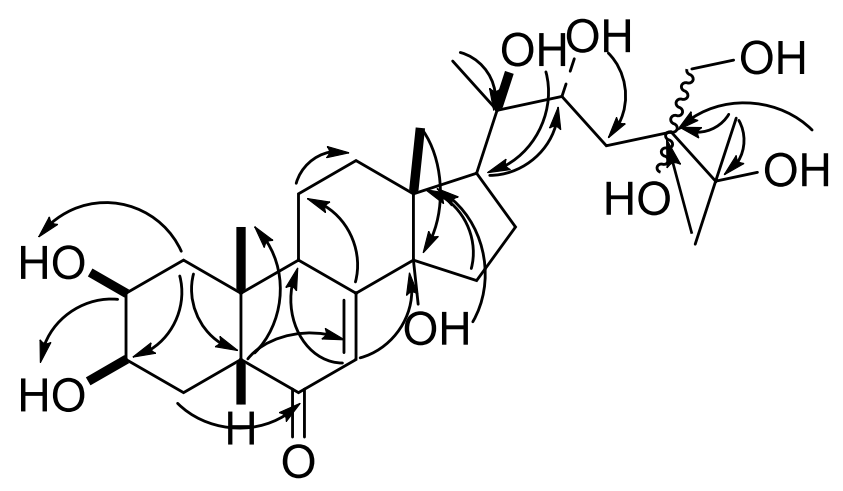

Fig. 4 Key HMBC correlations and chemical structure of compound 1 panuosterone, paxillosterone, 25-hydroxy-panuosterone, and 25-hydroxyatrotosterone [22, 23].

The COSY, ${ }^{13} \mathrm{C},{ }^{1} \mathrm{H}-{ }^{13} \mathrm{C}$ HSQC, as well as ${ }^{1} \mathrm{H}-{ }^{13} \mathrm{C}$ HMBC NMR spectra (Figures S8-S12, SM) indicated the presence of one carbonyl carbon $\left(\delta_{\mathrm{C}} 202.7\right)$, seven methine, eight methylene, five methyl carbons, and seven further carbons which were quite similar to that of the phytoecdysteroids mentioned above, and especially, to 20-hydroxy,24-hydroxymethylecdysone [21]. Compared to 20-hydroxy,24-hydroxymethylecdysone, the elemental composition only differed by one oxygen atom in $\mathbf{1}$, no proton signals could be observed at C-atom 24, and also the chemical shift of its carbon 24 of $41.4 \mathrm{ppm}$ is indicative. Exemplified selected key HMBC 


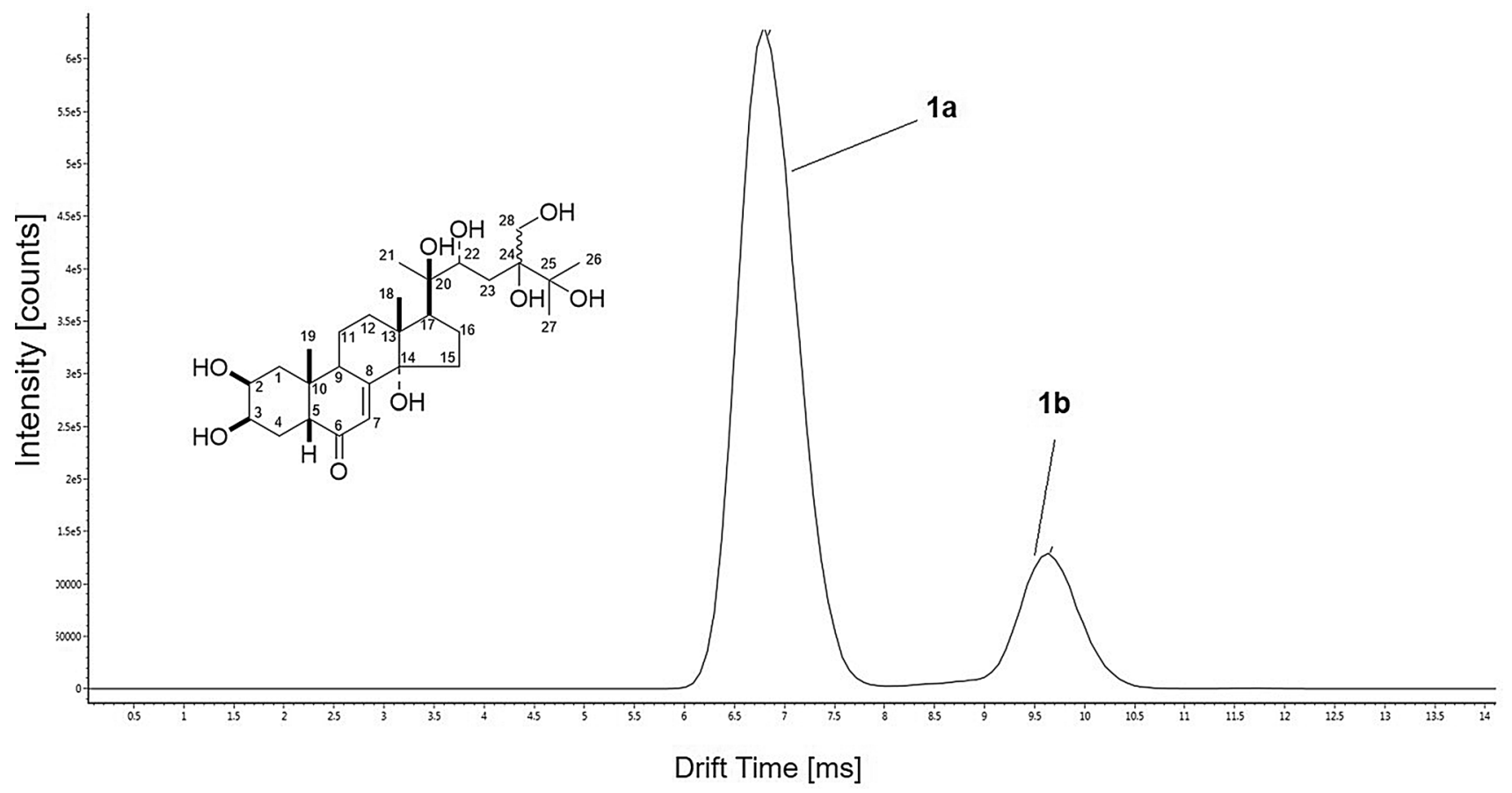

Fig. 5 Drift time distribution of compound 1

correlations are the coupling of $\mathrm{H}-(7)$ at $5.62 \mathrm{ppm}$ to $\mathrm{C}(9$ and 14), of $\mathrm{H}-(5)$ at $2.20 \mathrm{ppm}$ to the methyl group $\mathrm{C}(19)$ and of $\mathrm{H}_{3} \mathrm{C}-(18)$ to $\mathrm{C}(14)$. The correlation of the proton of the hydroxy function at position $\mathrm{C}(20)$ to the $\mathrm{C}$-atom (17) highlighted the linkage of the alkyl motif to the steroid system and the cross-coupling of the hydroxy function at position $\mathrm{C}(25)$ as well as of the two methyl groups 26, 27 to the C-atom (24) are indicative for the structure of the alkyl chain. Further important HMBC correlations are summarized in Fig. 4 and the complete assignments of ${ }^{1} \mathrm{H}$ and ${ }^{13} \mathrm{C}$ NMR signals are given in Tables SM1 and SM2. Consequently, the new compound 1 was named 20,24-dihydroxy,24-hydroxymethylecdysone. The absolute configuration of $\mathbf{1}$ at carbon 24 stays unclear, as on one hand no proton signals were located at $\mathrm{C}(24)$, which might help to disclose this information via chemical shift and potential coupling constants, and, on the other hand, literature data are puzzling. Vokac et al. determined the absolute stereochemistry of paxillosterone and panuosterone as [C-24R] or in 25-hydroxyatrotosterone as [C-24S] and in 25-hydroxypanuosterone supposed as [C-24R] with extensive NMR experiments including amongst others a derivatization step $[22,23]$. Darwish and Reincke indicated [C-24S] for makisterone C, 20-hydroxyecdysone, and 20-hydroxy,24-hydroxymethylecdysone, but no proof was stated in their work [21].

In principle, ecdysteroids represent an interesting group of natural compounds which play in insects a crucial hormonal role controlling molting and development [24]. Worth mentioning, in the light of this study, in plants, they appear to serve as part of the chemical defence against non-adapted herbivores [25], which might explain the high abundance of $\mathbf{1}$ just in the F1 sample. Ecdysteroids are unable to interact with the hormonal system of mammals, but despite of this, a number of rather beneficial metabolic effects have been attributed to humans: a mild anabolic activity of ecdysteroids undoubtedly exists, and these compounds can also influence both glucose and lipid homeostasis, altogether resulting in a so-called adaptogenic or "antistress" effect [26, 27]. 20,24-dihydroxy,24-hydroxymethylecdysone (1) is a new compound and may be used in further biological studies.

Recently, we highlighted mainly for polyphenols more than one drift time species by means of ion mobility separation, which we proposed to be hydrogen-bond stabilized conformers in the gas phase [19]. Again, for $\mathbf{1}$, two drift time species ( 6.83 and $9.65 \mathrm{~ms}$ ) could be detected which yielded a CCS of 222.2 and $304.1 \AA^{2}$ (Fig. 5). These two CCS values of $\mathbf{1}$ could be used now as new and additional characteristic compound parameters in compound identification/screening/database applications to reduce dereplication and false positives and strengthen the identification.

\section{Conclusion}

Non-targeted UPLC-ESI-TWIMS-TOF MS profiling of the aqueous ethanolic stem bark extract of $V$. cienkowskii revealed the new compound 20,24-dihydroxy,24-hydroxymethylecdysone (1) in high abundance sample F1, which, 
then, was isolated and chemically characterized. In plants, ecdysteroids play an important role in chemical defence against non-adapted herbivores, which might explain the high abundance of $\mathbf{1}$ just in the F1 sample. 1 showed two drift time species which could be used now as new and additional characteristic compound parameter in compound identification to reduce dereplication and false positives, and may be used in further biological studies on the glucose and lipid homeostasis.

Acknowledgements We wish to express our sincere thanks to the Alexander von Humboldt Foundation, for its award of Georg Forster Research Fellowship to one of the authors, and we are also grateful to the International Foundation of Science for his financial support (via Research Grant F/4633-2).

Funding Open Access funding provided by Projekt DEAL.

\section{Compliance with ethical standards}

Conflict of interest The authors declare that they have no conflict of interest.

Compliance with ethics requirements This article does not contain any studies with human or animal subjects.

Open Access This article is licensed under a Creative Commons Attribution 4.0 International License, which permits use, sharing, adaptation, distribution and reproduction in any medium or format, as long as you give appropriate credit to the original author(s) and the source, provide a link to the Creative Commons licence, and indicate if changes were made. The images or other third party material in this article are included in the article's Creative Commons licence, unless indicated otherwise in a credit line to the material. If material is not included in the article's Creative Commons licence and your intended use is not permitted by statutory regulation or exceeds the permitted use, you will need to obtain permission directly from the copyright holder. To view a copy of this licence, visit http://creativecommons.org/licenses/by/4.0/.

\section{References}

1. Arbonnier M (2004) Trees, shrubs and lianas of West African dry zones. CIRAD, MARGRAF Publishers GmbH, MNHN, Germany/France

2. Neuwinger HD (2000) African traditional medicine: a dictionary of plant use and applications. Medpharm Scientific Publishers, Stuttgart

3. Hoberg E, Orjala J, Meier B, Sticher O (1999) Diterpenoids from the fruits of Vitex agnus-castus. Phytochemistry 52:1555-1558

4. Ono M, Sawamura H, Ito Y, Mizuki K, Nohara T (2000) Diterpenoids from the fruits of Vitex trifolia. Phytochemistry 55:873-877

5. Ono M, Yamamoto M, Yanaka T, Ito Y, Nohara T (2001) Ten new labdane-type diterpenes from the fruit of Vitex rotundifolia. Chem Pharm Bull 49:82-86

6. Hajdu Z, Hohmann J, Forgo P, Martinek T, Dervarics M, Zupko I, Falkay G, Cossuta D, Imre M (2007) Diterpenoids and flavonoids from the fruits of Vitex agnus-castus and antioxidant activity of the fruit extracts and their constituents. Phytother Res 21:391-394

7. Nkeng-Efouet $P$ (1987) Contribution à l'étude des plantes médicinales du Cameroun: Les ecdysones et les irridoides des Vitex.
Thèse de doctorat 3e cycle en chimie organique, Faculté des Sciences, Université de Yaoundé, Cameroun

8. Kuruuzum-Uz A, Stroch K, Demirezer LO, Zeeck A (2003) Glucosides from Vitex agnus-castus. Phytochemistry 63:959-964

9. Sorensen JM, Katsiotis ST (2000) Parameters influencing the yield and composition of the essential oil from Cretan Vitex agnuscastus fruits. Planta Med 66:245-250

10. Wollenweber E, Mann K (1983) Flavonols from fruits of Vitex agnus-castus. Planta Med 47:126-127

11. Hirobe C, Qiao ZS, Takeya K, Itokawa H (1997) Cytotoxic flavonoids from Vitexagnus-castus. Phytochemistry 46:521-524

12. Dongmo AB, Azebaze AGB, Donfack FM, Dimo T, Nkeng-Efouet PA, Devkota KP, Sontia B, Wagner H, Sewald N, Vierling W (2011) Pentacyclic triterpenoids and ceramide mediate the vasorelaxant activity of Vitex cienkowskii via involvement of $\mathrm{NO} /$ cGMP pathway in isolated rat aortic rings. J Ethnopharmacol 133:204-212

13. Ramazanov NS (2004) Ecdysteroids and iridoidal glycosides from Vitex agnuscastus. Chem Nat Compd 40:299

14. Dongmo AB, Nkeng-Efouet PA, Devkota KP, Wegener JW, Sewald N, Wagner H, Vierling W (2014) Tetra-acetylajugasterone a new constituent of Vitex cienkowskii with vasorelaxant activity. Phytomedicine 21:787-792

15. Lang R, Wahl A, Stark T, Hofmann T (2011) Urinary N-methylpyridinium and trigonelline as candidate dietary biomarkers of coffee consumption. Mol Nutr Food Res 55:1613-1623

16. Stark T, Marxen S, Rütschle A, Lücking G, Scherer S, EhlingSchulz M, Hofmann T (2013) Mass spectrometric profiling of Bacillus cereus strains and quantitation of the emetic toxin cereulide by means of stable isotope dilution analysis and HEp-2 bioassay. Anal Bioanal Chem 405:191-201

17. Stark TD, Angelov A, Hofmann M, Liebl W, Hofmann T (2013) Comparative direct infusion ion mobility mass spectrometry profiling of Thermus thermophilus wild-type and mutant $\Delta$ cruC carotenoid extracts. Anal Bioanal Chem 405:9843-9848

18. Stark TD, Lösch S, Wakamatsu J, Balemba OB, Frank O, Hofmann T (2015) UPLC-ESI-TOF MS based metabolite profiling of the antioxidative food supplement Garcinia buchananii. J Agric Food Chem 63:7169-7179

19. Stark TD, Ranner J, Stiglbauer B, Weiss P, Stark S, Balemba OB, Hofmann T (2019) Construction and application of a database for a five dimensional identification of natural compounds in Garcinia species by means of UPLC-ESI-TWIMS-TOF-MS-Introducing gas phase polyphenol conformer drift time distribution intensity ratios. J Agric Food Chem 67:975-985

20. Suksamrarn A, Kumpun S, B-ek Yingyongnarongkul (2002) Ecdysteroids of Vitex scabra stem bark. J Nat Prod 65:1690-1692

21. Darwish FMM, Reinecke MG (2003) Ecdysteroids and other constituents from Sida spinosa L. Phytochemistry 62:1179-1184

22. Vokac K, Budesinsky M, Harmatha J, Kohoutova J (1998) Ecdysteroid constituents of the mushroom Tapinella panuoides. Phytochemistry 49:2109-2114

23. Vokac K, Budesinsky M, Harmatha J, Pis J (1998) New ergostane type ecdysteroids from fungi. Ecdysteroid of mushroom Paxillus atrotomentosus. Tedrahedron 54:1657-1666

24. Karlson P (1974) Mode of action of ecdysones. In: Burdette WB (ed) Invertebrate endocrinology and hormonal heterophylly. Springer, Berlin, pp 43-54

25. Schmelz EA, Grebenok RJ, Galbraith DW, Bowers WS (1998) Damage-induced accumulation of phytoecdysteroids in spinach: a rapid root response involving the octadecanoic acid pathway. $\mathrm{J}$ Chem Ecol 24:339-360

26. Báthori M, Tóth N, Hunyadi A, Márki A, Zádor E (2008) Phytoecdysteroids and anabolic-androgenic steroids. Structure and effects on humans. Curr Med Chem 15:75-91 
27. Foucault A-S, Mathé V, Lafont R, Even P, Dioh W, Veillet S, Tomé D, Huneau JF, Hermier D, Quignard-Boulangé A (2012) Quinoa extract enriched in 20-hydroxyecdysone protects mice from diet-induced obesity and modulates adipokines expression. Obesity 20:270-277
Publisher's Note Springer Nature remains neutral with regard to jurisdictional claims in published maps and institutional affiliations. 